
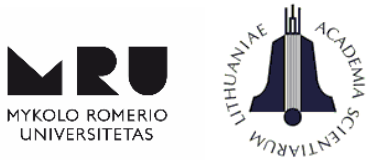

\title{
THE POLEMIC ON INVESTIGATION THE ECONOMICAL ESSENCE OF THE CATEGORY \\ "DISPROPORTION" IN THE CONTEXT OF ECONOMIC GLOBALIZATION
}

\author{
Anatolii VDOVICHEN \\ Chernivtsi trade and economic Institute of the Kyiv National trade- \\ economic University, Ukraine \\ E-mail: danjapolina@ukr.net
}

doi:10.13165/IE-14-8-2-09

\begin{abstract}
The paper grounds the necessity of considering the category "disproportionality" depending on the object and subject of study that enable two options for economic impacts state in an economic globalization - positive and negative, despite the terms laid down in negative terms of Philology.
\end{abstract}

JEL Classification: A12, B41, N01

Keywords: proportionality, disproportionality, disproportion, imbalance

\section{Introduction}

The growing role of the world economy integration processes in recent decades, consolidation of the globalization (as the main trend in the world economy) led to significant changes in the international division of labor, the nature and principles of global economic relations. Quantitative and qualitative differences involving individual countries to integration processes led to the formation of global economic disproportions. The contradictory nature of globalization is driven by rapidly developing science and technology, the mass character of modern production, the accelerated development of information and communication technologies etc. and at the same time by extremely unequal effects for different countries. Thus, the benefits multiply headmost of them and emit a narrow group of newly industrialized countries with significant potential for international competitiveness. 
With the expansion of economic, political, cultural interactions, globalization promotes disproportionality in various fields, creating a new level of global challenges, risks and threats. In the global economic development, primarily, it is gained increasing disproportional components of national wealth and reproductive structure of GDP, world trade in goods, services and capital markets, investment processes and territorial development leading to sectoral shifts in national economies and institutional disproportions.

All this determines the need for a holistic view of current macroeconomic changes in global scale and causes the relevance of basic research of global economic disproportions and risks impacting on the economy of any country in the context of the economic growth policy.

The aim of the paper is to identify the basic theoretical principles of the investigation the category "disproportions". Among the main objectives to achieve this goal one was to investigate the category of disparity in the general sense and in relation to its use in the economy, due to an essentially close to it terms and synonyms.

\section{Investigation the economical essence of the category "disproportion"}

Categories disparities, disparity, and disproportion, are the antonyms of words ratio and proportionality meaning mostly positive or neutral value, and disparities and disproportionality describing negative traits and phenomena.

The expressions proportion, proportionality defined in the most respected foreign dictionaries as share something in general, or the ratio of one phenomenon to another, the harmony between these parts, not necessarily whether it is numeric expression. For mathematical approach, vocabularies suggest a classic example of proportionality "four digits" - 2:6 = 3:9 [1, 2].

In other words categories disparities, disparity are defined as a certain deviation from the proportions, proportionality, and balance, as an attempt to achieve proportionality, regardless of whether these deviations are small or large.

The reviewing category "disproportions" needs to consider the interpretation of proportionality and disproportionality in economics. Interpretation of proportionality in the economy, according to the dictionary [3] (term disproportionality is absent in the dictionary) is defined as follows: "The proportions of economy (from lat. proportio) can be defined as the relations between the elements and units of production sectors, regions of the country and the countries that are formed as a result of socio-economic development of society and the influence of other factors (historical, natural, political, scientific, technological etc.) "[3].

In this context, unlike disparities (and disproportionation), above mentioned categories are relatively neutral, i.e. proportionality mainly can be considered as a reflection on the socio-economic phenomena in modern conditions, or in comparison with the past or prospective state, i.e. in two different dimensions - in statics and dynamics.

Interpretation of the term "disparity" for the economy is given in the Encyclopedia [4] and defined as "a violation of proportions in the development of certain sectors of the economy, economic units (means of production and the production of consumer goods) and 
overlapped phases of production, resulting in irregularities during playback of certain spheres or the economy in general. The disproportion is manifested as violations of necessary links between production and consumption "[4].

The above-mentioned portion of the definition the expression "disproportions" is mainly focused on the economic conditions of socialism (although it is not directly stated). Let us consider the interpretation from the point of view of capitalism where the same phenomena and manifestations are determined from other ideological positions: "Disproportion - one of the most distinctive features of capitalist economy development to be in constant violation in the course of capitalist reproduction of necessary relationships between sectors and elements of production. The disproportion is the result of the domination of private ownership by the means of production, increased competition and anarchy of production. Common distortions take the form of periodic economic crises of overproduction "[4].

In another Encyclopedia [5] there is emphasized that the overall disproportions "are present only in capitalism, they are associated with shocks to the economy and the reproduction process as a whole and are of long and recurring character" but socialist economy inherent "harmonious development, consistency and proportionality "[5].

Economic quantitative indicators that could be clearly defined as disparities probably do not exist. The same economic indicators and the proportions may be considered one subject as positive and among other as a negative and disproportionate.

The term "disparity" is not often used in economic literature, but practically all economic studies on the economic and mathematical models, theoretical statistics, accounting theory and macro-microeconomics more or less related to the analysis of disproportionality aspects. The papers of macro- and microeconomics are related to disproportionality and imbalance, although do no use these terms directly. Earlier, the analysis of the foreign economy, including the effects of disproportionality, was mostly connected with the term "crisis".

Perhaps we can agree that any socio-economic proportions contain certain elements of disproportions, and when its negative quantitative characteristics cross to quality, they can be seen and treated as disparity and imbalances. However, it should be noted that any conventional quantitative indicators (such as the temperature of the human body is considered higher than $37 \mathrm{deg}$. $\mathrm{C}$ as high) practically do not exist.

The paper of famous Ukrainian economist W. Geyts [7] is almost entirely devoted to numerous aspects of disproportionality, but the term "disproportionate" is used directly only once, at p. 87, in spite of the fact that it could be used on other pages without any restrictions [7]. Instead, the scientist uses dozens of similar terms that directly express the "disproportionality" - for example, instability, asynchronous, deficit/surplus of the consolidated budget, unpaid salaries, pensions, excessive depreciation of fixed assets, uneven development, inequality between countries and regions, the gap between developed countries 
and developing country, the polarization of incomes, adverse changes in industry structure and other.

The analysis of the foreign references until 2008 allowed making the conclusion that the problems of disproportionality in the context of stress and attention to it are mostly distributed in the groups of economists who specialize in economic and mathematical methods of research and less on macroeconomics. We must agree that they are available and present in almost all socio-economic phenomena to any extent, but they are mostly considered and analyzed without special accentuation of the term. The attention to the category in question and the frequency of its use increased in pre-crisis and crisis periods 2007-2010.

The detection and elimination of at least the majority of socio-economic disparities in the economic literature is considered in the context of supply and demand, and they are thoroughly considered in all foreign textbooks on macroeconomics [8].

The terms disparity and imbalance are much more important in statics and dynamics. In the static approach they to be in almost all economic and social phenomena and in dynamics it can be divided into two vectors - the first helping to negotiate them, the second increases the disparity and imbalance. For example if the rate of increase in GDP per capita in developing countries is higher than the same rate in developed countries, we can talk about some trends of negotiating disproportionality. Moreover, if in the first group of countries these rates are two to three times more than in the second then it is treated as a significant rate of overcoming the uneven development, and if, say, they are only $10-20 \%$ more, we have a very slow, slight performance of decreasing the existing disproportionality.

Consequently, much of the data presented in statistical sets of countries, the UN and other international organizations can be considered as the base for the analysis of disproportionality and imbalance of numerous socio-economic indicators in statics and dynamics.

As to statistical and quantitative expression of disproportionality, one of the most suitable techniques for this can be considered as the ratio between the maximum and minimum values of the indices to be compared.

We can rather say with great confidence that there are at least two fundamental requirements for statistical analysis of proportionality, without which the conclusions either impossible or they will be inaccurate, wrong and in many cases these conditions are not met. The first - the objects to be compared should be the same, the second (abut comparing structural disproportions) - it must be identical (in modern terms it is international classification). For example, when comparing the structures of the industry on the international level it should be used on the base of international "Classification of Business Activities", and on any country level - national classification of economic activities.

The leading international business publications had drawn special attention to the need for observing the strict conditions regarding compliance of the statistics presented in statistical collections or the analysis in economic research, to the realities of economic and social processes which they reflect, especially in those where the emphasis is focused on disproportionality. Thus, the United Nations Development Programme (UNDP) describes the 
need for attention to the quality of statistical data: "The Millennium Development Goals have made clear necessity for relevant, reliable, timely statistics to set policies, control decisionmakers, monitor progress and evaluate results. Yet despite considerable improvements in recent years, meeting the demand for basic data on human development remains a major global challenge". "Lacking appreciation of the importance of statistics in supporting informed decision-making, too many countries are trapped in a circle of low demand and low resources for statistics, resulting in inadequate supply. Such countries do not routinely collect data - many have not conducted a population census in the past 10 years - and lag far behind in the adoption of up-to-date statistical standards and methods. They also have limited capacity to analyze and disseminate statistics, discouraging the use of data in national policy analysis. Demand for data must increase if national statistical systems are to break this circle of underperformance and to underfund. Efforts to increase the supply of data must also strengthen the capacity of governments and the general public to use data effectively." [9].

This document provides the basic requirements for the quality of statistics, including compliance with international classifications and standards. The report provides specific and generalized examples of the limited applicability of statistics, especially in developing countries and countries in Central and Eastern Europe [9]. The Millennium Development Goals highlight areas where national statistical systems require dramatic improvements. Many countries, including the top and high priority countries require extensive assistance to conduct regular surveys of income and consumption-especially to assess extreme poverty and basic living conditions. Such countries also need to develop or strengthen statistical programmes for other social indicators, particularly for health data [9]. One can cite other examples of statistical imbalances (disparency) in the economy, both on international and country level.

The overall conclusion with the respect to this problem is that the statistics describing the manifestations of disproportionality should be analyzed from the perspective of reality and not to be used purely mechanical. Certainly, this is not an easy requirement, and these quite complex methodological and practical aspects must be settled by statistical agencies, and not by users of statistical data. However, in some cases, the contradiction between the real situation and the statistics are so egregious that they cannot be overlooked.

We have already suggested that disparity of socio-economic phenomena is not some new manifestation of the process of historical development, which appeared only in recent years. In the historical literature, ranging from the ancient world of ancient Rome, Greece, the Middle East, India, China we can find many examples of "disproportionality" regarding living conditions, the economy and trade. Hundreds of examples are describing disproportionality the socio-economic situation of the Middle Ages and the early formation of capitalism are in the famous three-volume work of French scientist Fernand Braudel "Everyday Economics".

The most serious and global research that was published in the middle of the last century and laid the foundation for further development and a sort of "specialization" of these studies should provide monograph of American authors Woytinskies "World Population and Production. Trends and Outlook "[10]. It can be cited hundreds of examples of socioeconomic 
disproportionality between countries in the Woytinsky`s work, but we admit the following two examples from the brief comments of the authors. Describing the consumer needs of the population, they note that "the needs, real or imagined, have no restrictions in our Western civilization. Satisfying one desire causes and stimulates new desires. This dissatisfaction needs a double consequence: a basis for dynamic development of the existing socio-economic system and a common understanding of dissatisfaction reasoned by statistical data that clearly characterizes startling disparities in the consumption of products of agricultural origin" [10].

Among numerous foreign studies on various aspects of disproportionality it should not go unnoticed the fundamentally new approaches to methodology and practice comparing GDP/GNP and its components (for end use) among countries not by the official exchange rate, but on the basis of purchasing power parities (PPP) of national currencies against the U.S. dollar. It is a collective research that was carried out by three joint institutions - the Statistical Department of the Secretariat of the United Nations, the World Bank and the University of Pennsylvania [11]. The first phase of these comparisons for 1967 was made on the example of 6 countries with different levels of development and different geographic regions of the world - Britain, India, Kenya, the USA, Hungary and Japan, and the second phase by 1970 further raised four countries - Italy, Colombia, France and Germany.

The research had showed significant differences between the per capita level of the main macroeconomic indicators of the gross national product (which since 1967 has been replaced by GDP at official exchange rates) and PPP, especially on the major components of the index. Now this method of comparisons is "adopted" and widely used in all major international comparisons between countries characterizing disproportionate aspects of the socio-economic development of countries.

Two sessions of Project LINK, which took place in November 2006 in Geneva (Switzerland) and in May 2007 in Beijing (China) reviewed five reports on the problems of economic imbalance. We should note that these materials use the term "imbalance" but not "disproportion". The materials indicate economic disproportionality analysis in the development of individual groups of countries and regions in comparison with the global trend and characteristics of China's economic development in comparison with other countries, particularly with India.

In general it can be stated that the term "imbalances", that has a negative connotation is often used in English and other languages in contrast to the positive meaning of the word "balance". So the term «imbalance» is not mentioned in the most authoritative English dictionary «The Concise Oxford Dictionary» [1], where it would have had to be placed on p. 593. However, in the same American Dictionary «Webster's New World Dictionary of the American Language» [2] here is a half of line in one of two columns (p. 725) - "lack of balancing (balance) on proportionality, state functions, etc.". Great Soviet Encyclopedia (edition 1983) gives an explanation of the term only in the physical-mechanical sense, as a "deviation from the axis in the machines" [4].

Most likely, at least in modern economic literature, the term "disparity" is wider, and the "imbalance" narrower compared with the term "disproportionality". Classically, the term 
"balance" in an economic sense is based on the presence of the ratio of two mandatory parts (elements) - availability of resources and its use. Imbalance should be seen as a lack of equality between the required parts that included in the system of balance and the terms "balance" and "imbalance" should preferably be used to describe phenomena in statics but not in dynamics. Perhaps one of the most common examples of imbalances is the consolidated budgets; they are approved in excess of expenditure over income (sometimes - vice versa) in most cases. And at the stage of preparing total cost exceeds potential revenues.

Concerning the fact that the expression "proportionality" or "disparity" has a broader interpretation (compared with term imbalance), for example, exploring the age structure of women, the ratio should be interpreted as "disproportionate" and unlikely it cannot be used the term "imbalance" because balancing these disproportions in the balanced system is impossible a priori, given the importance of natural factors.

That is, in the Project LINK the term «imbalance» could be reports replaced by others close to it terms without any loss of content that are often used in economic literature. Most likely its first mention caused a "chain reaction" for further use in the title of this project.

Thus, in the SelimElekdag`s report (IMF) "Modeling the Adjustment of Global Imbalances: the IMF experience " (Geneva, November 2006) the term «imbalance» mentioned in two of the five basic thesis - on motivation fluctuations of global imbalances and review scenarios manifestation of imbalance. It is present also in the the report by Peter Paul and Joseph Rotman (University of Toronto) "The global economic imbalances, reviewed results" (May 2007, Beijing); key findings - the pace of development in developing countries (especially China and India) has exceeded that of developed countries. Report by Rob Vos and Pingfan Hong (UN Secretariat)" How China Could Contribute to a Benign Global Rebalancing" (Beijing, May 2007) also refers to the known deviations from the average in statics and dynamics.

The conclusions of the above document states that governments and international economic organizations should conduct mutual consultations and seek to achieve a greater degree of consensus to overcome and mitigate the uneven development and the necessary of strengthening mediation concerning the effectiveness, efficiency recommendations aimed at reducing the symptoms of imbalance. The special role of China to be seen from the perspective of an ever-increasing amounts of foreign exchange reserves and the objectivity of its exchange rate and trade policy.

That is, familiarity with data reports leads to the conclusion that the term «imbalance» to be used by international organizations, is just one of the many other synonyms that are often used to characterize the economic development of countries, regions and the whole world in statics and dynamics. Although, in our opinion, in this case, better to use the category of "disproportionality."

If you do not consider these issues in historical terms it should be noted that in prewar times (forties) real possibility of "quality" studying disparities at the international level was very limited in terms of modern requirements. For example, as it is published in the 
League of Nations Statistical Yearbook (1946), there are only national data on a fairly limited number of countries and the data is not based on the same methodology (this applies to most natural indicators) and do not allow their reduction in regional or world totals.

Apparently only, foreign trade statistics was some exception where the requirements for application of the same product classifications are prioritized, without them no one could conduct foreign trade and adopted the so-called Brussels International Trade Classification.

Thus, the major international studies on structural comparisons and identifying the disparities began in the postwar years. One of the most important international document aimed to overcome some most extreme disproportionality globally should be considered "Millennium Declaration". The Millennium Declaration has eight chapters and key objectives, adopted by 189 world leaders at the summit: The Declaration, after the Vienna Declaration and Programme of Action, stresses the observance of international human rights law and international humanitarian law under the Principles of United Nations Charter as well as the treaties on sustainable development [12]:

1. Values and Principles

- Freedom

- Equality

- Solidarity

- Tolerance

- Respect for nature

- Shared responsibility

2. Peace, Security and Disarmament

3. Development and Poverty Eradication

4. Protecting our Common Environment

5. Human Rights, Democracy and Good Governance

6. Protecting the Vulnerable

7. Meeting the Special Needs of Africa

8. Strengthening the United Nations [12]

For each of the goals of the Millennium Declaration, it can be cited numerous statistical tables and dozens of pages of the text analytic material. Basic and very disappointing conclusion is that over the last decade more than 50 countries (which is more than a quarter of the world) became poorer.

\section{Conclusions}

Thus, the disparity should be considered depending on the object and subject of study that enables to state two variants of economic impacts - positive and negative, despite the terms laid down in negative terms of Philology.

It is necessary to isolate the following basic types of disparities: disparities in levels of economic and social development between groups of countries, states, internal regional disparities within countries and other regional imbalances, macroeconomic 
imbalances - fundamentals and other countries; structural imbalances of GDP - by sector, cost structure, end-use; internal disparities status and development of real sector, imbalances between production factors - labor and capital; imbalances as a significant tool to identify, analyze and eliminate disparities - analysis of the basic balance of the country and international comparison.

\section{References}

1. The Concise Oxford Dictionary of Current English. Oxford University Press. Oxford. 2011. ISBN 978-0199601080 (book).

2. Victoria Neufeldt, David Bernard Guralnik. Webster's New World Dictionary of American Language. Macmillan General Reference; Leather edition (March 1990). ISBN-10: 0139492984

3. Political economics, M. Politizdat, 1983, p. 364.

4. Bolshaya Sovetskaya Encyclopedia, ed. 3-e, v. 8, p. 311-312, by V. Katz.

5. Ukrainian Soviet Encyclopedia. V. 3, 1980, p. 378, by V. Kazantsev.

6. Igor Shumilo. Wha is the truth about economic growth in Ukraine? "ZerkaloNedeli» № 19, 19 May2007.

7. ValeriyHeyets Instability and Economic Growth, Kyiv, 2000.

8. Campbell R. McConnell and Stanley L. Brue. Economics, Volume 2, Chapter 22.

9. Human Development Report 2003. Millenium Development Goals. Box 2.1, p. 35. New York, 2003.

10. W.S. Woytinsky and E.S. Woytinsky «World Population and Production. Trends and Outlook ». The Twentieth Century Fund. New York, 1953, 1268 pp.

11. Irwing B. Kravi, Zoltan Kenessey, Alan Heston, Robert Summers «A System of International Comparisons of Gross Product and Purchasing Power». The Johns Hopkins University Press. Baltimore and London, 1975, 294 pp.

12. United Nations General Assembly Resolution 2 session 55 United Nations Millennium Declaration on 18 September 2000.

\section{About the Author:}

Anatolii VDOVICHEN -Associate professor, Chernivtsi trade and economic Institute of the Kyiv national trade-economic University, Ukraine, Phd., Chair of international Economics.

Research interests: the disproportion between the development of the world economy, investment activity and the problems of regional development. 